\author{
Boleslaw GORANCZEWSKI ${ }^{1}$ \\ Anna SZELIGA-KOWALCZYK ${ }^{2}$
}

\title{
KLIENT WEWNĘTRZNY A KULTURA ORGANIZACYJNA
}

\begin{abstract}
Celem artykułu jest przedstawienie wpływu kultury organizacyjnej na klienta wewnętrznego z perspektywy przejawów takich jak symbole, sposoby komunikowania się i rytuały, a także czterech typów kultury zawartych w modelu wartości konkurujących. Zaprezentowano również współczesne nurty występujące w kulturze organizacyjnej i ich oddziaływanie na klienta wewnętrznego. Artykuł ma charakter przeglądowy. Drugi i trzeci rozdział wprowadza czytelnika w istotę klienta wewnętrznego oraz kultury organizacyjnej $\mathrm{w}$ świetle literatury przedmiotu. Czwarty i piąty rozdział ukazuje odpowiednio interakcje, jakie zachodzą pomiędzy klientem wewnętrznym subiektywnie sklasyfikowanym przez autorów, a przejawami i typami kultury organizacyjnej oraz jej trendami charakterystycznymi dla współczesności. Autorzy wnioskują, że w największej mierze klientowi wewnętrznemu nie sprzyja kultura hierarchiczna, natomiast najlepsze warunki do współpracy i nawiązania partnerskich relacji w działaniu stwarza kultura kooperacyjna. Zwracają uwagę na fakt, że współcześnie następuje hybrydyzacja kultur. Powstają także kultury nietypowe stanowiące wyznacznik obecnych czasów takie jak na przykład kultura indywidualistyczna, które ze względu na swój wysoki stopień elastyczności stanowią dobre środowisko dla funkcjonowania klienta wewnętrznego. Takie atrybuty kultury organizacyjnej jak: symbole, sposób komunikowania się, czy rytuały mają duży wpływ na klienta wewnętrznego rozpatrywanego przez autorów $\mathrm{w}$ każdej $\mathrm{z}$ przyjętych trzech perspektyw. W artykule zastosowano analizę literatury przedmiotu oraz ze względu na nikły dorobek literaturowy odnoszacy się do klienta wewnętrznego, inspiracje i koncepcje własne oparte na bazie doświadczeń praktycznych zdobytych przez autorów w organizacjach różnego typu.

Słowa kluczowe: interesariusz, dostawca, podejście procesowe, artefakty, wartości.
\end{abstract}

\section{WPROWADZENIE}

Człowiek w organizacji kreuje jej kulturę i wreszcie kultura ma wpływ na człowieka,

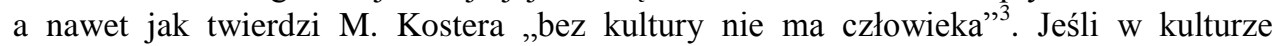
organizacyjnej widoczne lub odczuwalne są aspekty związane z klientem wewnętrznym, można mówić o jego świadomym istnieniu. Jeśli nie, wówczas klient wewnętrzny pozostaje w sferze idei lub koncepcji.

Pojęcie klienta wewnętrznego jest jak dotąd bliżej niedookreślone. Traktowanie go wyłącznie jako pracownika (ujęcie HR - owe) lub uczestnika rynku wewnętrznego (ujęcie

\footnotetext{
${ }^{1}$ Dr Bolesław Goranczewski, Wyższa Szkoła Bankowa we Wrocławiu, ul. Fabryczna 29-31, 53-609 Wrocław, autor korespondencyjny: e-mail: boleslaw.goranczewski@wsb.wroclaw.pl,; Energa SA, ul. Grunwaldzka 472, 80-309 Gdańsk,+48726300105

${ }^{2}$ Dr Anna Szeliga-Kowalczyk, Wyższa Szkoła Bankowa we Wrocławiu, ul. Fabryczna 29-31, 53609 Wrocław, anna.szeligakowalczyk@wsb.wroclaw.pl, +48508072910

3 M. Kostera, Antropologia organizacji. Metodologia badań terenowych, Warszawa 2013, s. 34 .
} 
marketingowe) w opinii autorów jest dalece niewystarczające. Na potrzeby niniejszego artykułu przyjęto autorską, trójwymiarową klasyfikację klienta wewnętrznego, który rozumiany jest jako:

1) interesariusz wewnętrzny;

2) komórka/ stanowisko $\mathrm{w}$ strukturze organizacyjnej $\mathrm{z}$ różnymi pespektywami odniesienia;

3) klient wewnętrzny w ujęciu procesowym.

Interesariusz wewnętrzny to pracownik, właściciel, akcjonariusz, udziałowiec, przedstawiciel związków zawodowych itp. Pion/komórka organizacyjna/stanowisko w strukturze organizacyjnej to również klient wewnętrzny, dla którego tworzy się i dostarcza określone produkty/usługi wewnętrzne. Ostatni - trzeci wymiar - klient wewnętrzny $\mathrm{w}$ ujęciu procesowym jest jedynym zdefiniowanym bytem zawartym w normie terminologicznej ISO $9000^{4}$. Idea klienta wewnętrznego wywodzi się z filozofii Total Quality Management. Postuluje się w niej, aby kreować w organizacji kulturę jakości. Tworzenie kultury jakości polega między innymi na zmianie świadomości, czym jest jakość wyników organizacji oraz jaki jest wpływ na te wyniki klienta wewnętrznego uczestniczącego w procesach tworzenia wartości dodanej ${ }^{5}$.

Praca ma charakter przeglądowy i traktuje o wpływie kultury hierarchicznej, rynkowej, kooperacyjnej oraz kultury kreacji/tworzenia na klienta wewnętrznego. Typy tych kultur ujęto w modelu wartości konkurujących, a zatem charakteryzują się one dużą odmiennością. Autorzy analizują również wpływ przejawów kultury organizacyjnej oraz współczesnych trendów kulturowych na istotę bytu klienta wewnętrznego. Wynikiem tych analiz są wskazania kultury „najbardziej przyjaznej” dla egzystencji klienta wewnętrznego.

\section{KLIENT WEWNETRZNY W ŚWIETLE LITERATURY PRZEDMIOTU}

Literatura światowa w zakresie klienta wewnętrznego jest stosunkowo uboga. Opiera się na wynikach prac badawczych publikowanych bardzo rzadko w czasopismach naukowych ${ }^{6}$.

Pierwsze prace badawcze pojawiają się w latach dziewięćdziesiątych XX wieku i ujmują klienta wewnętrznego w zakresie wąskim/jednowymiarowym. Na przykład praca z 1996 r. autorstwa R. Hallowell, L. A. Schilesinger i J. Zornitsky Internal Service

\footnotetext{
${ }^{4}$ PN-EN ISO 9000:2006, Systemy zarządzania jakościa, podstawy i terminologia, wyd. PKN, Warszawa 2006, pkt 3.3.5. za: B. Goranczewski, A. Szeliga-Kowalczyk, Jakość ustug turystycznych i rekreacyjnych, ujęcie holistyczne, Warszawa 2015, s. 176.

5 Por. E. Krodkiewska-Skoczylas, G. Żarlicka, Zarzadzanie relacjami z klientem [w:] Klient w organizacji zarządzanej przez jakość, red. T. Sikora, Kraków 2006.

${ }^{6}$ Por. J.R. Hauser, D.I. Simester, B. Wernerfelt, Internal Customers and Internal Suppliers, „Journal of Marketing Research" 33/3 (VIII,1996), s. 268-280; R.F. Brooks, I.N. Lings, M.A. Botschen, Internal Marketing and Customer Driven Wavefronts, „Service Industries Journal” 19/4 (X, 1999), s. 49-67; M. Jun, Sh. Cai, Examining the Relationships Between Internal Service Quality and its Dimensions, and Internal Customer Satisfaction, „Total Quality Management” 21/2(II, 2010), s. 205-223; K. Gurjeet, R.D. Sharma, N. Seli, An Assessment of Internal Market Orientation in Jammu and Kashmir Bank Through Internal Suppliers' Perspective, „Journal of Management Research" 7/2 (2008), s. 149-176; R. Mosahab, O. Mahamad, T. Ramayah, Comparison of Service Quality Gaps among Teachers and Students as Internal and External Customers, „International Journal of Marketing Studies" 2/2 (XI, 2010), s. 13-20.
} 
Quality,Ccustomer and Job Satisfaction: Linkages and Implications for Management ${ }^{7}$ traktuje, iż gwarantem zapewnienia odpowiedniej jakości usług świadczonych klientom zewnętrznym jest wcześniejsze zaspokojenie potrzeb klientów wewnętrznych rozumianych jako pracownicy. Zmienną objaśnianą jest w tym przypadku satysfakcja pracowników z pracy. Autorzy publikacji badają wpływ składowych jakości usług wewnętrznych na satysfakcję z pracy. Zaledwie kilka prac w wyżej wskazanym okresie traktuje klienta wewnętrznego w szerszym zakresie, tzn. klient wewnętrzny - dostawca wewnętrzny ${ }^{8}$.

Jedynie w normie terminologicznej PN-EN ISO 9000:2006 przedstawiono następującą definicję klienta, która „dotyka” pojęcia klienta wewnętrznego, otóż klient to „organizacja lub osoba, która otrzymuje wyrób. Klient może być wewnętrzny lub zewnętrzny w stosunku do organizacji”" . Przy czym wyrób/usługa jest wynikiem procesu, czyli zbioru działań wzajemnie powiązanych lub wzajemnie oddziałujących, które przekształcają wejścia w wyjścia. Klient wewnętrzny to interesariusz wewnętrzny, komórka organizacyjna, która otrzymuje część pracy wykonanej przez kogoś innego/dostawcę wewnętrznego, a następnie wzbogaca ten produkt lub usługę o własny wkład, by przekazać wyrób kolejnemu klientowi. Klient wewnętrzny jawi się w podejściu procesowym organizacji - powiązania między procesami stanowią bowiem łańcuch klientów wewnętrznych, gdzie każdy korzysta w wyrobów dostawców/klientów wewnętrznych.

Zwrócenie uwagi na klienta wewnętrznego spowodowało m.in. że hasło „,klient nasz pan" nabiera szerszego wymiaru i odnosi się zarówno do klienta wewnętrznego jak i zewnętrznego, którzy zostali zrównani w swoich prawach i obowiązkach, gdzie organizację traktuje się jako podmiot zaspokajający szeroko rozumiane potrzeby klienta. W praktyce często jednak prawdziwość ww. hasła staje się wątpliwa i jest pomijana $\mathrm{w}$ organizacjach $\mathrm{w}$ stosunku do klienta wewnętrznego przez twórców polityki jakości, a częściej nawet poszczególni pracownicy nie są świadomi, kto jest ich klientem wewnętrznym ${ }^{10}$.

Wagę klienta wewnętrznego podkreśla również norma ISO $9001^{11}$, zgodnie z którą nie ma różnicy pomiędzy klientem zewnętrznym i wewnętrznym.

Powodzenie zarządzania procesem zależy przede wszystkim od jakości komunikacji i współpracy pomiędzy klientami i dostawcami w całej organizacji. Rozpatrując działalność organizacji w kontekście jednego ogólnego procesu, na który składają się procesy cząstkowe, należy uwzględnić, że każdy kto bierze udział w ogólnym procesie ma swój własny zestaw wymagań (potrzeb, oczekiwań). Spełnienie tych wymagań gwarantuje prawidłowe wykonanie każdej czynności w procesie, natomiast ich

${ }^{7}$ R. Hallowell, L.A. Schilesinger, J. Zornitsky, Internal Service Quality, Customer and Job Satisfaction: Linkages and Implications for Management, „Human Resource Planning” 19/2 (1996), s. $20-31$.

${ }^{8}$ Por. J. R. Hauser, D. I. Simester, B. Wernerfelt, op. cit., s. 268-280; R.F. Brooks, I.N. Lings, M.A. Botschen, op. cit., s. 49-67.

${ }^{9}$ PN-EN ISO 9000:2006, op. cit., pkt 3.3.5.

10 Por. J. Bank, Zarządzanie przez jakość, Gebethner \& Ska, Warszawa 1996; M. Bugdol, Zarzadzanie przez jakość, zagadnienia społeczne, wyd. Uniwersytetu Opolskiego, Opole 2003; Cz. Sikorski, Zachowania ludzi w organizacji, PWN, Warszawa 2002.

${ }^{11}$ PN-EN ISO 9001:2009, Systemy zarzadzania jakościa. Wymagania, wyd. PKN, Warszawa 2009. 
niespełnienie zmniejsza jego skuteczność i efektywność. Wymagania klienta wewnętrznego są przekazywane - w procesach cząstkowych - od klienta do dostawcy, a zgodność z wymaganiami w kierunku przeciwnym, od dostawcy do klienta (rys. 1).

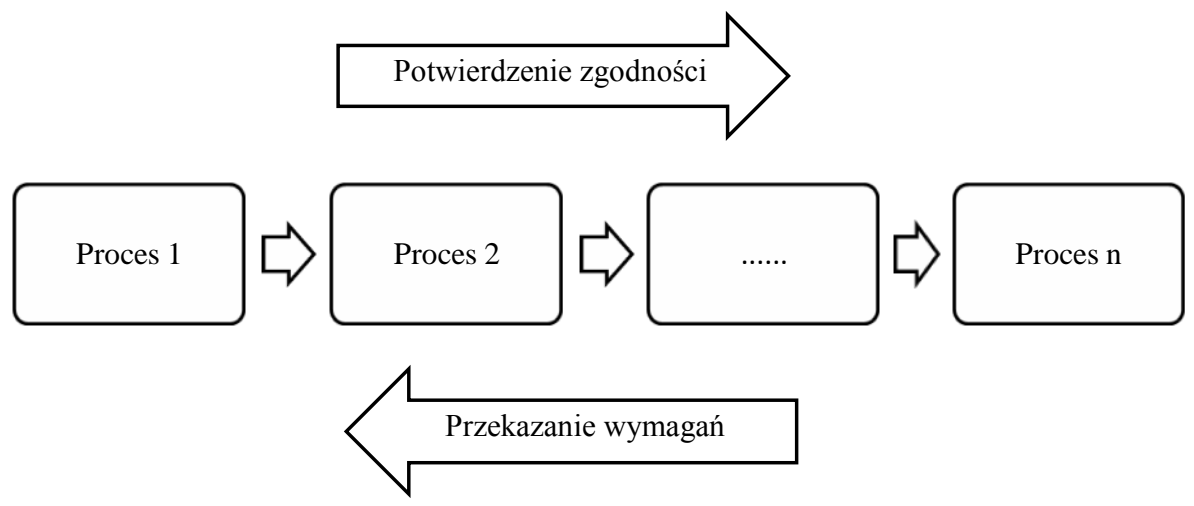

Rys. 1. Klient wewnętrzny

Źródło: opracowanie własne na podstawie J. Kowalczyk (red.), ,Kodeks” dobrej praktyki zarzadzania $w$ organizacjach turystycznych, MSiT, Warszawa 2008 [online]

\section{NURTY, FUNKCJE I KONEKST WYMIARÓW KULTURY ORGANIZACYJNEJ}

W przeciwieństwie do klienta wewnętrznego kultura organizacyjna jest szeroko opisywana w literaturze przedmiotu. Jest również przedmiotem licznych badań reprezentowanych $\mathrm{w}$ naukach społecznych i humanistycznych. W efekcie prac badawczych powstało dziesiątki definicji sformułowanych przez antropologów czy badaczy innych dyscyplin naukowych, jak chociażby z zakresu zarządzania potencjałem społecznym $\mathrm{HR}^{12}$. Aktualny dorobek w tym zakresie uwidacznia główne nurty:

1. Kultura jest zbiorem cech, atrybutów organizacji, używając języka terminologii jakościowej właściwości inherentnych, a więc przypisanych do danego konkretnego obiektu, w tym przypadku organizacji. Zatem kultura istnieje w organizacji.

2. W drugim nurcie wskazuje się, iż organizacja jest kulturą. Stanowi z nią określoną tożsamość, jest bytem nierozdzielnym, ponieważ zarówno organizacja jak i kultura konstytuowana jest przez wartości, wzorce, postawy, zachowania w tym ich

\footnotetext{
12 Por. A.L. Kroeber, C. Kluckhohn, Culture: A critical review of concepts and definitions, (Peabody Museum of American Archeology and Ethnology Papers 47), Cambridge 1952; A. Frank, J. Brownell, Organizational Communication and Behaviour: Communicating to Improve Performance, Holt, Rinehart \& Winston, Orlando 1989; L. J. Mullins, Management and organisational behaviour, „Pearson education”, 2007; Cz. Sikorski, Kultura organizacyjna w instytucji, Łódź 1990; L. Zbiegień-Maciąg, Kultura organizacji. Identyfikacja kultur znanych firm, Warszawa 2005, s. 13 i n.
} 
akceptowalność bądź odrzucenie, jak również skuteczność / wewnętrzna dynamika w osiąganiu zaplanowanych rezultatów ${ }^{13}$.

W literaturze przedmiotu wyszczególnia się określone charakterystyki kultury. Uwzględniając aspekt kliencki poszczególne funkcje można scharakteryzować następująco:

1. Poznawcze - pracownicy nabywają nowych doświadczeń w wyniku szkoleń, komunikowania się $\mathrm{z}$ innymi zdobywania wiedzy i umiejętności od starszych doświadczonych pracowników. Kreowane są opinie nie tylko w sprawach zawodowych/zakładowych, ale także ogólnych, pozazawodowych. Pracownicy profesjonalizują się, uczą stosunku/relacji do klienta, poznają reguły poprzez pryzmat formalizmów i reguł postępowania $\mathrm{z}$ klientami.

2. Adaptacyjne - w organizacji obowiązują określone schematy postępowania, procedury, język komunikowania się. Następuje samoistna dyfuzja zachowań, postaw, wartości, języka, które przekładają się i oddziałują na życie poza organizacją. Funkcja adaptacyjna odnosi się także do hierarchii poznania i akceptacji władzy zarówno formalnej jak i nieformalnej, wolności i ograniczeń panujących w organizacji. Nowi pracownicy uczą się podejścia do klienta, zwyczajowego czy nieformalnego, niejednokrotnie wymuszonego indywidualną sytuacją (np. kryzysową).

3. Integracyjne - kultura tworzy wspólnotowość przynależność w efekcie bycia razem, hołdowania tym samym wartościom, uczuciom, wzorcom postępowania. Wszystko to skupione jest wokół celów jakie organizacja lub jej właściciele mają do zrealizowania. Ma to swoje bezpośrednie przełożenie na klienta, na wartość jaką mu dostarcza zgodnie z ideą tworzenia wartości dla klienta ${ }^{14}$.

Innym przykładem opisywania kultury organizacyjnej jest kontekst jej wymiarów, wśród których wyszczególnić można ${ }^{15}$ :

1. Dystans władzy - stopień hierarchizacji struktury - wysoka centralizacja, silosy/grona organizacyjne, struktury smukłe ze wszystkimi wadami i pionowymi zniekształceniami komunikacyjnymi. Dystans władzy wiąże się ze sprzeciwem wobec głosu szefa $\mathrm{w}$ zależności od stylu kierowania (autokrata vesrus lider); z tym się wiążą postawy konformistyczne, koncyliacyjne, spolegliwość lub ich przeciwieństwo otwartość i odwaga, asertywność. Z dystansem władzy wiąże się dystans emocjonalny pomiędzy przełożonymi i pracownikami. W sytuacji niewielkiego dystansu pracownicy nie mają oporu do wyrażania własnych opinii, w przypadku dystansu dużego występuje silna zależność podwładnych od kierownika co powoduje obawy w zakresie swobodnego wypowiadania opinii ${ }^{16}$.

2. Indywidualizm lub kolektywizm. Zależy w dużej mierze od pozycji w organizacji; im niższy szczebel, tym bardziej adekwatny jest kolektywizm, im wyżej - następuje naturalna tendencja do indywidualizacji sukcesów, pomysłów itp. W kulturach, gdzie występuje silna zależność od władzy następuje kolektywizm.

13 K.S. Cameron, R.E. Quinn, Kultura organizacyjna. Diagnoza $i$ zmiana, Wolters Kluwer, Warszawa 2015, s. 27 i n.

${ }^{14}$ Zob. L. Zbiegień-Maciąg, op. cit., 36 i n.

15 Por. B. Kożusznik, Zachowana człowieka w organizacji, Warszawa 2011, s. 262 i n.; G. Hofstede, G.J. Hofstede, Kultury i organizacje, Warszawa 2007 s. 53 i n.

${ }^{16}$ G. Hofstede, G.J. Hofstede, op. cit., s. 58. 
3. Unikanie niepewności - to sytuacja, w której organizacje wolą, aby działania, procesy i funkcje były sformalizowane, zaprogramowanie dokumentacji między innymi po to, aby unikać błędów $\mathrm{W}$ przeciwnym wypadku występuje ryzyko wystąpienia niezgodności np. nietrafnych, niepożądanych decyzji. Zaprogramowane $\mathrm{w}$ formalizmach decyzje zapewniają redukcję niepokoju. Przed strachem i niepewnością zabezpieczać powinny zwyczaje i wartości, np. wiara, przestrzeganie zasad bezpieczeństwa w ramach wykonywanego zawodu, profesjonalizacja oparta na kompetencjach zawodowych. Z niepewnością i skłonnością do podejmowania ryzyka ma także związek płeć oraz różnica wieku i idąca w ślad za tym wrażliwość oraz tolerancja do akceptacji niepewności i ryzyka.

4. Kobiecość i męskość - charakteryzuje się współpracą w przypadku kobiet, rywalizacją zaś w przypadku mężczyzn. Nastawieniem na igrzyska, zamiast kooperacji i traktowania celów jako wspólnej sprawy realizowanej we współpracy. Atrybuty męskie prowadzą do autokracji i rywalizacji, natychmiastowych terminów rozwiązania problemów, determinacji i zdyscyplinowania. Kobiecość i męskość wpływa na sposoby rozwiązywania konfliktów. W organizacjach, w których nie ma odpowiednich proporcji/równowagi płci, klimat organizacyjny jest najczęściej zaburzony. W przypadku modelu męskości dominuje potrzeba zwyciężania, w przypadku modelu kobiecości występuje potrzeba kompromisu. Wynika to z uwarunkowań socjokulturowych albowiem mężczyzna musi utrzymać rodzinę. W kulturach, gdzie występuje matriarchat dominujące jest nastawienie na niesienie pomocy wzajemnej i możliwości kontaktów międzyludzkich. Te dwa modele kulturowe mają swoje implikacje w kontekście klienta wewnętrznego. Klient wewnętrzny zawsze potrzebuje kooperacji i współpracy, empatii i zrozumienia. Podejście kobiecości w kulturze powoduje migracje z totalnego podporządkowania się współczesnym korporacjom w kierunku artykułowania wartości. W poniższej tabeli scharakteryzowano to zjawisko (tabela 1).

Dynamika zmian, mieszanie się kultur $\mathrm{z}$ ich pozytywnymi i negatywnymi skutkami powoduje systematyczny proces transformacji i przewartościowania. Jest to szczególnie widoczne w dużych korporacjach, gdzie dominuje wyścig szczurów, gdzie podporządkowuje się życie prywatne „dobremu” w subiektywnej ocenie miejscu pracy. Gdzie tworzy się idealne środowisko dla powstawania dysfunkcji społecznych takich $\mathrm{jak}^{17}$ :

- konflikty w organizacji;

- pracoholizm;

- wypalenie zawodowe;

- mobbing/bullying;

- wyścig szczurów.

\footnotetext{
${ }^{17}$ A. Szeliga-Kowalczyk, Zmienność procesów a dysfunkcje spoleczne w organizacji [w:] Społeczne aspekty zarzadzania procesami, red. E. Mazur-Wierzbicka, P. Zwiech, Szczecin 2016, s. 22-32.
} 
Tabela 1. Kultura organizacji z perspektywy płci

\begin{tabular}{|l|l|}
\hline $\begin{array}{l}\text { Kultura nastawiona na rywalizację, brak } \\
\text { kooperacji i calkowite podporządkowanie z } \\
\text { perspektywy męskości }\end{array}$ & $\begin{array}{l}\text { Kultura nastawiona na wartości } \\
\text { uniwersalne z perspektywy kobiecości }\end{array}$ \\
\hline Praca jako cel istota i sens wszystkiego & Praca, uczucia, nauka, jestestwo \\
\hline Pieniądze przedmiotem dążeń & Sens istnienia jako przedmiot dążeń \\
\hline $\begin{array}{l}\text { Wykorzystanie zasobów, głównie ludzi, } \\
\text { nadmierna eksploatacja aż do wypalenia i } \\
\text { pozbycia z organizacji }\end{array}$ & $\begin{array}{l}\text { Utrzymanie zasobów a zwłaszcza potencjału } \\
\text { społecznego }\end{array}$ \\
\hline $\begin{array}{l}\text { Awansuj w najszybszym możliwym czasie } \\
\text { (skokowo) }\end{array}$ & Rozwijaj się ewolucyjnie w naturalny sposób \\
\hline Praca kosztem rodziny & Work life balance ${ }^{18}$ \\
\hline
\end{tabular}

Źródło: opracowanie własne na podstawie: J. Godfrey, Our Wildest Dreams: Women Enterpreneurs Making Money, Having Fun, Doing Good, „Harper Business”, New York 1992, pp. 53-70.

\section{WPLYW KULTURY ORGANIZACYJNEJ NA KLIENTA WEWNECTRZNEGO}

Klienta wewnętrznego rozpatrywać można zasadniczo w trzech kategoriach:

1) Interesariusza wewnętrznego (w tym pracownika);

2) Komórki / stanowiska w strukturze organizacyjnej z różnymi pespektywami odniesienia oraz

3) W ujęciu procesowym, jedynym zdefiniowanym, w którym jest on najpełniej widoczny.

Powyższa klasyfikacja będzie stanowić kryterium odniesienia do analizy wpływu kultury organizacyjnej na klienta wewnętrznego z perspektywy:

1) przejawów kultury;

2) czterech typów kultury zawartych w modelu wartości konkurujących.

Perspektywa przejawów kultury w kontekście klienta wewnętrznego jest istotna, ponieważ specyfikuje, często trudne do identyfikacji, atrybuty kultury zawierające się w trzech poziomach symptomatycznych ${ }^{19}$ :

1) artefaktów - namacalnych doświadczeń odnoszących się do produktów usług czy zachowań, postaw i zwyczajów wewnątrzorganizacyjnych;

\footnotetext{
${ }^{18}$ Por. A. Szeliga-Kowalczyk, Work - Life Balance as Seen by Women, based on own research, „Proceedings of IAC-MEM 2016 in Bratislava”, 6-7 VII 2016.

${ }^{19}$ E. Schein, Organizational Culture and Leaderschip, San Francisco 1992, s. 17.
} 
2) wartości, które są uznane w organizacji - a więc powody, dla których organizacja zachowuje się w taki a nie inny sposób;

3) podstawowych założeń - charakteryzujących się tym, że w organizacji do pewnych tematów podchodzi się zupełnie bezkrytycznie i bez zbędnego konstatowania (np. w służbach mundurowych).

W nieco odmiennym ujęciu, bezpośrednim i widocznym przejawem kultury jest klimat organizacyjny stanowiący emanację różnych właściwości, które się na nią składają ${ }^{20}$.

Perspektywę Modelu Wartości Konkurujących w odniesieniu do analizy wpływu kultury organizacyjnej na klienta wewnętrznego zastosowano ze względu na fakt, iż jest to uznane $\mathrm{w}$ świecie naukowym, jak również w świecie praktyków zarządzania narzędzie pomiarowe $^{21}$.

\subsection{Przejawy kultury}

Każda organizacja charakteryzuje się pewnymi atrybutami, które widoczne są dla pracowników, klientów czy pozostałych interesariuszy. Przejawiają się one w postawach, zachowaniach, sposobie bycia, ubierania się, komunikowania, wyposażeniu, nastawieniu do współpracowników i osób z zewnątrz ${ }^{22}$. Pierwszym z nich są symbole, następnie sposób komunikowania się oraz rytuały.

\subsubsection{Symbole}

Wśród tej grupy przejawów rozróżnić można aranżację wnętrz organizację, poziom dbałości o infrastrukturę, design, organizację czy rozplanowanie pomieszczeń. Ponadto sposób ubierania wyglądu (dres code stosowany w wielu organizacjach) identyfikatory, a także symbolika związana z przynależnością do hierarchii w strukturze organizacyjnej, jak samochód służbowy, wyposażenie w markowy sprzęt osobisty, telekomunikacyjny oraz IT, dostępność do wydzielonych stref, obszarów budynków w zależności od statusu, kafeterie, gratisy, jak chociażby karty płatnicze z ustalonym limitem itp. Symbolika pozwala uczestnikom porozumiewać się, przeżywać określone wyobrażenia czy skojarzenia, a także wartościować zdarzenia i zjawiska ${ }^{23}$.

Z pespektywy klienta wewnętrznego symbolika ma znaczenie następujące:

1) Interesariusz wewnętrzny - inaczej do symboliki będą podchodzić właściciele, inaczej zarządy a inaczej związki zawodowe. $Z$ jednej strony dbałość o koszty, z drugiej podkreślenie korzyści i przywiązania się do przywilejów, czy jak w przypadku związków zawodowych do postaw roszczeniowych. Jak pisze M. Kostera, w kontekście symboli i ich interpretacji „, w rzeczywistości [...] istnieje o wiele więcej możliwości oceny, interpretacji, czy nawet widzenia fragmentów rzeczywistości. Symbole są nośnikami kultury i umożliwiają nam jej czytanie" ${ }^{24}$.

2) Komórki/stanowiska w strukturze organizacyjnej - w odniesieniu do symboli sama struktura pozostaje bez znaczenia, może oddziaływać jedynie na klienta wewnętrznego tworząc atmosferę, ergonomię, dostępność do zasobów, czy realizację

\footnotetext{
${ }^{20}$ B. Kożusznik, op. cit., s. 259. cit., s. 40 i n.

${ }^{22}$ Zob. L. Zbiegień-Maciąg, op. cit., s. 43 i n.

${ }^{23}$ M. Kostera, op. cit., s. 33 .

${ }^{24}$ Ibidem, s. 32.
}

${ }^{21}$ Por. K.S. Cameron, R.E. Quinn, R.E. DeGraff, A. Thakor, Compenting Values Leadership: Creating Value in Organizations, Edward Elgar, Northampton 2006; K.S. Cameron, R.E. Quinn, op. 
celów własnych np. w przypadku ruchomego czasu pracy (przy zagwarantowaniu niezbędnej wspólnej dla komórek kooperujących interakcji w czasie rzeczywistym).

3) Klient wewnętrzny w ujęciu procesowym - symbolika nie ma tutaj istotnego wpływu. Procesy są w zasadzie uniewrażliwione na tego typu oddziaływanie. Jedyny wpływ, jaki jest możliwy to odniesienie symboliki do technicznego wyposażenia procesów i ich zdolności do spełniania wymagań (np. stan/nowoczesność infrastruktury).

\subsubsection{Sposób komunikowania się}

Komunikowanie jest ściśle związane z wielkością organizacji, jej formą, strukturą językiem korporacyjnym i/lub technicznym. Przejawia się sposobem obsługi klienta zewnętrznego, sposobami podejmowania gości itp. Komunikacja ma istotne znaczenie w środowisku międzykulturowym, gdzie występuje zjawisko etnocentryzmu rozumianego jako deprecjonowanie innych kultur na rzecz standardów występujących w kulturze rodzimej ${ }^{25}$.

1) Interesariusz wewnętrzny - komunikowanie ma istotny wpływ, zależne jest od grupy docelowej. Inne przekazy będą dla właścicieli np. akcjonariuszy, inne dla analityków a jeszcze inne dla związków zawodowych. Chodzi głównie o język i formę przekazu. Analitycy potrzebują przekazu specjalistycznego, a inni interesariusze jak chociażby związki zawodowe oczekują prostoty, zrozumiałego i czytelnego. W przypadku klientów wewnętrznych wszelkie bariery komunikacyjne mogą wywołać poczucie złości, bezsilności, poczucia niższości, agresji spadku motywacji, czy poczucia braku zainteresowania.

2) Komórki/stanowiska w strukturze organizacyjnej. Inaczej komunikują się służby IT $w$ ramach wewnętrznych struktur używając języka technicznego, inaczej w odniesieniu do komórek biznesowych, funkcjonalnych, gdzie język informatyczny nie jest zrozumiały. Inaczej komunikują się podmioty w ramach dużych struktur używając języka korporacyjnego, inaczej w małych podmiotach gospodarczych. Język komunikowania zależny jest od znajomość kodów, którymi się posługuje (rysunek, techniczny, algorytm czy słowo pisane). W przeciwnym razie tworzą się bariery i utrudnienia komunikacyjne wpływające na skuteczność pracy.

3) Klient wewnętrzny w ujęciu procesowym - algorytmy postępowania, schematy blokowe, opisy procedur, instrukcji, dokumentacja techniczno-ruchowa. Wszystko to może być przekazywane za pośrednictwem języka naturalnego, formuł matematycznych, schematu blokowego, grafu, wykresu itp. w zależności od przyjętego w systemie i zrozumiałego dla użytkowników kodu.

\subsubsection{Rytuały}

Dotyczą głównie gestów. Gesty są szczególnie istotne w biznesie międzynarodowym. Dotyczy to zwłaszcza komunikacji niewerbalnej, gdzie można zastąpić słowa, wprowadzać dodatkową ekspresję przekazu. Należy przy tym uważać, aby nie narażać organizacji na nieprzyjemności, w sytuacji gdy pogwałcamy w ten sposób reguły i zasady kulturowe $^{26}$. To samo dotyczy klienta wewnętrznego, wobec którego należy stosować powszechnie i zwyczajowo $\mathrm{w}$ danej organizacji obowiązujące wspólnie akceptowane gesty.

\footnotetext{
${ }^{25}$ M. Bartosik-Purgat, Otoczenie kulturowe w biznesie międzynarodowym, Warszawa 2010, s. 55 i n.

${ }^{26}$ Ibidem, s. 109 i n.
} 
4.2. Model Wartości Konkurujących

Kolejnym kryterium odniesienia dla analizy klienta wewnętrznego oraz determinantów jego funkcjonowania jest model wartości konkurujących. W modelu tym występują cztery kategorie kultur organizacyjnych zawierających wartości, które ze sobą konkurują.

\subsubsection{Kultura hierarchiczna}

Jest pierwszym typem kultury zawartym w modelu i odnosi się do administracyjnego nurtu w zarządzaniu, budowanego na formalizmach, rozbudowanych strukturach, które posiadają szereg atrybutów mogących oddziaływać na organizację w postaci ${ }^{27}$ :

- smukłości organizacji;

- rozpiętości kierowania;

- zasięgu kierowania;

- nadmiernej specjalizacji;

- $\quad$ konfiguracji i koordynacji;

- formalizacji, a także

- standaryzacji.

W tego typu organizacji dąży się do stabilności, trwałości funkcjonowania. Miarą skuteczności działania jest terminowość, konsekwencja działania. Dominującym czynnikiem oddziaływania zaś jest kontrola. Kultura hierarchiczna przejawia się głównie w administracji publicznej ale też w dużych korporacjach. W odniesieniu do klienta wewnętrznego:

1) Interesariusz wewnętrzny - w odniesieniu do dobra, które wytwarza dostawca na rzecz klienta wewnętrznego, kultura hierarchiczna powoduje usztywnienia oparte na formalizmach bez możliwości jakichkolwiek odstępstw. Klient wewnętrznypracownik jest obsługiwany, ale $w$ granicach plenipotencji, w ramach formalnych reguł postępowania. $\mathrm{Z}$ punktu widzenia właściciela jego oczekiwaniem jako klienta wewnętrznego jest przestrzeganie obowiązujących reguł i zasad. Niewątpliwie model ten jest adekwatny do takich oczekiwań.

2) Komórki/stanowiska w strukturze organizacyjnej - formalne procedury postępowania powodują, że komórka lub podmiot otrzymują wszystko dokładnie i na czas. Problemy pojawiają się wówczas, gdy produkt wewnętrzny wymaga innowacji lub gdy zmieniają się potrzeby bądź oczekiwania klienta wewnętrznego Wówczas skostniałe, nieelastyczne struktury powodują bezwład organizacyjny uniemożliwiający szybką reakcję na dokonanie niezbędnych zmian.

3) Klient wewnętrzny w ujęciu procesowym - w wielu organizacjach stosowane są jednoczesne podejście strukturalne i procesowe. Są one jednak względem siebie przecwiskuteczne. Nakładanie na rozbudowane struktury organizacyjne zmapowanych procesów powoduje jeszcze większe trudności w zarządzaniu. Obydwa podejścia wykorzystują rozbudowaną dokumentację, w efekcie czego jej znajomość w dużych organizacjach przez poszczególnych pracowników jest nikła.

\footnotetext{
27 B. Goranczewski, Struktury $i$ procesy $w$ organizacjach ukierunkowanych na jakość, Prace
} Naukowe Wyższej Szkoły Bankowej w Gdańsku, Gdańsk 2011t. 13, s. 35-58. 


\subsubsection{Kultura rynkowa}

Charakteryzuje się rywalizacją, odnosząca się głównie do funkcjonowania w oparciu o mechanizmy transakcji rynkowych. Jest mniej zorientowana na kontrolę funkcjonalną. Dotyczy głównie podmiotów komercyjnych i/lub grup o powiązaniach kapitałowych, gdzie głównym celem jest oczekiwany wzrost wartości, dobry standing finansowy itp. Główną miarą skuteczności jest efektywność ekonomiczna (rentowność) oraz prawidłowa realizacja celów.

1) Interesariusz wewnętrzny $-\mathrm{z}$ punktu widzenia właścicieli najbardziej odpowiednia forma organizacji, ponieważ dla tej grupy klientów wewnętrznych głównym oczekiwanym produktem wewnętrznym jest wzrost wartości przedsiębiorstwa, mierzony wskaźnikami kapitałowymi. Z perspektywy klienta wewnętrznego -pracownika ten model kultury jest optymalny, ponieważ produkt wewnętrzny powstaje jako efekt nastawienia na zaspokojenie potrzeb klienta zewnętrznego. $\mathrm{Z}$ innej zaś perspektywy rywalizacja i podnoszenie norm ilościowych może powodować, że ten sam klient wewnętrzny, będący jednocześnie dostawcą wewnętrznym będzie ulegał dysfunkcjom takim jak chociażby wypalenie zawodowe ${ }^{28}$.

2) Komórki/stanowiska w strukturze organizacyjnej - oczekiwany wzrost wartości wymusza jakość, stąd komórki otrzymują produkt wysokiej jakości zaspokajający potrzeby. Prowadzi też do rywalizacji (konkurencji). Na przykład istnieje możliwość zakupu usługi $\mathrm{w}$ podmiocie dedykowanym $\mathrm{w}$ ramach struktury korporacyjnej, jednocześnie tą samą usługę można kupić w podmiocie zewnętrznym (niezależnym). Możliwość wyboru zawsze korzystnie odbija się na jakości.

3) Klient wewnętrzny w ujęciu procesowym - kluczowymi miernikami w tym podejściu są skuteczność i efektywność. Kultura rywalizacji sprzyja efektywności działań i procesów. Zatem ten model kultury jest najbardziej adekwatny dla organizacji stosujących podejście procesowe.

\subsubsection{Kultura kooperacji}

Dotyczy organizacji, które są oparte na silnych więziach współpracy, hołdowaniu tym samym wartościom czy pracy zespołowej. W zależności od czynników sytuacyjnych kultura klanu może być lepsza od rywalizacyjnej lub gorsza. Zależy to na przykład od kondycji finansowej czy pozycji rynkowej. Z punktu widzenia klienta zewnętrznego najlepsza. Traktuje go jak partnera. O ile kultura rywalizacyjna jest tam, gdzie następują szybkie i dynamiczne zmiany, o tyle w kulturze klanu wszelkie zmiany odbywają się w sposób ewolucyjny.

1) Interesariusz wewnętrzny - najlepsza $\mathrm{z}$ perspektywy pracownika, ponieważ podobnie jak klienta zewnętrznego również $\mathrm{i}$ pracownik $\mathrm{w}$ tym modelu traktowany jest po partnersku. Z punktu widzenia interesariusza-właściciela, dla którego najważniejszym produktem, jaki otrzymuje jest akceptowalny poziom wyniku finansowego, przy jednoczesnym zadowoleniu pozostałych interesariuszy - jest modelem kultury optymalnym. Z perspektywy związków zawodowych, dla których jako klienta wewnętrznego produktem są środowisko, atmosfera, warunki pracy i płacy, kultura kooperacji jest lepsza niż kultura

\footnotetext{
${ }^{28}$ A. Szeliga-Kowalczyk, Teachers' occupational burnout syndrome, „Jagiellonian Journal of Management" 4/2015, s. 353-367.
} 
rywalizacyjna, gdzie występują takie negatywne zjawiska jak wyścig szczurów, psucie relacji czy rozbijanie więzi.

2) Komórki/ stanowiska w strukturze organizacyjnej - model lepszy od rywalizacyjnego, ponieważ dostawca traktuje komórkę partnersko szczegółowo uzgadniając stosowne wymagania.

3) Klient wewnętrzny w ujęciu procesowym. Z perspektywy procesów lepsza, niż w modelu rywalizacyjnym, albowiem ukierunkowana na systematyczne doskonalenie i współpracę z dostawcą.

4.2.4. Kultura kreacji/tworzenia

Kultura adhokracji ${ }^{29}$ odnosi się do ery informacyjnej i pracowników wiedzy. Do organizacji najbardziej elastycznych, gdzie nie ma czasu na tworzenie sformalizowanych struktur, które równie szybko powstają, co z znikają. Są organizowane dla realizacji określonych projektów, zleceń czy inicjatyw. Są to organizacje ukierunkowane na innowacje, wdrażanie rozwiązań, nowatorskie rozwiązywanie problemów, gdzie dominuje perspektywa i wyobraźnia. Miernikami funkcjonowania tej kultury są zmiana, nowatorskie podejście i operatywność działania.

1) Interesariusz wewnętrzny - w zasadzie model ten nie ma wpływu na klienta wewnętrznego. Jedyne co łączy ludzi w tego typu organizacjach to idea lub wynagrodzenie. Podstawowym atrybutem tej formy organizacyjnej jest bowiem tymczasowość jest istnienia.

2) Komórki/stanowiska w strukturze organizacyjnej - wszelkiego rodzaju formalizmy rzadko występują w tym modelu kultury, a zatem pozostaje ona bez wpływu na klienta wewnętrznego.

3) Klient wewnętrzny w ujęciu procesowym - w związku z brakiem formalnych struktur ich miejsce zajmują procesy, a zatem ten model jest najbardziej adekwatny dla klienta wewnętrznego w ujęciu procesowym.

\section{WSPÓLCZESNE NURTY W KULTURZE ORGANIZACYJNEJ I ICH WPLYW NA KLIENTA WEWNETRZNEGO}

Przedstawione powyżej przejawy kultury, jak również model wartości konkurujących, nie są jedynymi. Przykładem odpowiadającym kulturze rywalizacyjnej w modelu wartości jest kultura indywidualistyczna związana z digitalizacją informacji, procesów, technologii itp. Wynika z profesjonalizacji, specjalizacji, wysokiego poziomu wiedzy i umiejętności. Istotą jest tutaj samodyscyplina, motywacja wynikająca $\mathrm{z}$ osobistych pobudek, jak również ambicji czy prestiżu społecznego itp. ${ }^{30}$ Jest ona następstwem kolektywistycznych modeli kultury epoki postindustrialnej opartej na powtarzalności procesów działań i pracy zespołowej. W kulturze indywidualistycznej produktem wewnętrznym są wysokiej jakości, trudne realizacyjnie produkty wewnętrzne, a zatem klient wewnętrzny stawia bardzo wysokie i ambitne wymagania dostawcom.

Kolejnym trendem jest kultura sieci organizacyjnych, których występowanie związane jest $\mathrm{z}$ globalizacją, koncentracją kapitału itp. Sieci organizacyjne nie ingerują w wartości. Nie próbują ograniczać indywidualnego charakteru. Jednocześnie stanowią środowisko

\footnotetext{
${ }^{29}$ K.S. Cameron, R.E. Quinn, op. cit., s. 51 i n.

${ }^{30}$ Cz. Sikorski, Kierunki zmian w kulturach organizacyjnych [w:] Metody zarzadzania kultura organizacyjna, red. Ł. Sułkowski, Cz. Sikorski, Warszawa 2014, s. 39 i n.
} 
dla standaryzowania praktyk organizacyjnych, aby stabilizować więzi pomiędzy uczestnikami sieci, równoważyć strategię ogólną ${ }^{31}$. Standaryzacja ma w zasadzie pozytywną konotację w odniesieniu do klienta wewnętrznego.

Kultura proinnowacyjna tworząca odpowiednie środowisko dla kreowania i wdrażania projektów, pomysłów itp. musi się charakteryzować odpowiednimi atrybutami takimi jak $^{32}$ :

- elastyczność, otwartość, odwaga (właściwa postawa) wobec zmian, doskonalenie się (zdobywanie wiedzy i umiejętności);

- interdyscyplinarność zespołów - w kulturze proinnowacyjnej produktem wewnętrznym są idee i pomysły powstające w oparciu o efekt synergii;

- tolerancja dla niepewności i niezamierzonych błędów;

- ukierunkowanie na sukces i doskonalenia;

- zaangażowanie w sprawy organizacji i zaufanie;

- partycypacja w zarządzaniu oraz zmniejszenie dystansu władzy;

- $\quad$ kooperacja współpraca i dzielenie się wiedzą;

- odpowiednie przywództwo.

Powyższa specyfikacja cech kultury proinnowacyjnej w pełni w praktyce nie występuje lub występuje bardzo rzadko. W takim środowisku zarówno klient, jak i dostawca wewnętrzny ma odpowiednie dla siebie środowisko.

Z perspektywy klienta wewnętrznego istotne jest występujące obecnie zjawisko crosswergencji lub hybrydyzacji kultury. Polega ono na tym, że względy kulturowe nie pozwalają wprost przenosić rozwiązań skutecznych w jednym obszarze kulturowym do drugiego. Zatem menedżerowie działając w danym kręgu kulturowym powinni dokonywać fragmentarycznego wyboru tych cech, które się sprawdziły i przenosić do innych kręgów kulturowych tworząc w ten sposób mieszankę kulturową ${ }^{33}$. Dobrym przykładem są koła jakości, które sprawdziły się zarówno w Japonii jak i USA. Przy czym pracownicy japońskich przedsiębiorstw zajmowali się doskonaleniem własnej pracy po jej godzinach. Amerykanie zaś stwierdzili, że owszem idea kół jest dobra, jednakże mogą oni w nich uczestniczyć w ramach czasu pracy.

\section{PODSUMOWANIE}

Analiza przejawów kultury organizacyjnej wykazuje, iż symbolika ma istotny wpływ na interesariuszy wewnętrznych, z kolei sposób komunikowania się oraz rytuały implikują istotnie na klienta wewnętrznego we wszystkich trzech formach klasyfikacji przyjętej w niniejszym artykule.

Analiza różnych typów kultur organizacyjnych unaoczniła, że nie sprzyja klientowi wewnętrznemu między innymi kultura hierarchiczna, która charakteryzuje się nadmiernym formalizmem, brakiem elastyczności, skostnieniem struktur, co z kolei powoduje bezwład organizacyjny. Potrzeby i oczekiwania klienta wewnętrznego zaspokajanie są w minimalnym zakresie uregulowanym formalizmami. Optymalnym

\footnotetext{
${ }^{31}$ J. Bieńkowska, Kultura sieci [w:] Metody zarzązania kulturą..., s. 139 i n.

32 D. Chmielewska-Muciek, Kultura innowacji, [w:] Kompetencje $i$ kultura organizacyjna przedsiębiorstw $w$ perspektywie międzynarodowej, red. A. Sitko-Lutek, Lublin 2014, s. 180 i n.

${ }^{33}$ M. Kostera, M. Śliwa, Zarządzanie w XXI wieku. Jakość, twórczość, kultura, Warszawa 2012, s. 113.
} 
rozwiązaniem z punktu widzenia klienta wewnętrznego jest kultura rynkowa, która zaspokaja jego potrzeby i oczekiwania, lecz $\mathrm{z}$ drugiej strony sprzyja rywalizacji prowadzącej do takich dysfunkcji jak wypalenie zawodowe, pracoholizm. Niewątpliwie jednak kultura rywalizacji wspiera efektywność działań i procesów, dlatego ten model kultury jest najbardziej adekwatny dla organizacji stosujących podejście procesowe. Podobny stosunek do klienta wewnętrznego przejawia kultura kreacji/tworzenia Organizacje/interesariusze wewnętrzni są dynamiczni, przedsiębiorczy i kreatywni, lecz niejednokrotnie przeciążeni, gdyż dominuje tutaj rywalizacja i stres spowodowany niepewnością, niejednoznacznością i nadmiarem informacji.

Najlepszym rozwiązaniem z punktu widzenia klienta wewnętrznego jest kultura kooperacyjna nastawiona na współpracę i partnerskie relacje w działaniu. Zdecydowanie lepsza od kultury rywalizacyjnej, gdyż ukierunkowana przede wszystkim na systematyczne doskonalenie organizacji, co z kolei stanowi wspólny mianownik z kulturą jakości.

Analiza współczesnych trendów odnoszących się do kultur organizacyjnych wskazuje, iż następuje hybrydyzacja kultur. Nie występują one w czystej postaci np. kultura stricte hierarchiczna lecz w praktyce występują zindywidualizowane dla każdej organizacji mieszanki kultur. Tworzą się także kultury nietypowe stanowiące wyznacznik obecnych czasów takie jak: kultura indywidualistyczna, sieci organizacyjnych, proinnowacyjna, charakteryzujące się wysoką elastycznością często stanowią odpowiednie środowisko dla klienta wewnętrznego. W każdej $\mathrm{z}$ nich można zauważyć atrybut standaryzacji/powtarzalności, który jest podstawą zarządzania jakością. Nurty te sprzyjają zatem klientowi wewnętrznemu, a także kreacji kultury jakości.

\section{LITERATURA}

[1] Bank J., Zarządzanie przez jakość, Gebethner \& Ska, Warszawa 1996.

[2] Bartosik-Purgat M., Otoczenie kulturowe w biznesie międzynarodowym, PWE, Warszawa 2010.

[3] Bieńkowska J., Kultura sieci [w:] Metody zarzadzania kultura organizacyjna, red. Ł. Sułkowski, Cz. Sikorski, Difin, Warszawa 2014.

[4] Brooks R.F., Lings I.N., Botschen M.A., Internal Marketing and Customer Driven Wavefronts, „Service Industries I.N. Journal” 19/4 (X,1999), s. 49-67.

[5] Bugdol M., Zarzadzanie przez jakość, zagadnienia społeczne, wyd. Uniwersytetu Opolskiego, Opole 2003.

[6] Cameron K.S., Quinn R.E, Kultura organizacyjna. Diagnoza i zmiana, Wolters Kluwer, Warszawa 2015.

[7] Cameron K.S., Quinn R.E., DeGraff R.E., Thakor A., Compenting Values Leadership: Creating Value in Organizations, Edward Elgar, Northampton 2006.

[8] Chmielewska-Muciek D., Kultura innowacji [w:] Kompetencje i kultura organizacyjna przedsiębiorstw $w$ perspektywie międzynarodowej, red. A. SitkoLutek, wyd. UMCS, Lublin 2014.

[9] Frank A., Brownell J., Organizational Communication and Behaviour: Communicating to Improve Performance, Holt, Rinehart \& Winston, Orlando 1989. 
[10] Godfrey J., Our Wildest Dreams: Women Enterpreneurs Making Money, Having Fun, Doing Good, „Harper Business”, New York 1992, s. 53-70.

[11] Goranczewski B., Struktury $i$ procesy $w$ organizacjach ukierunkowanych na jakość, Prace Naukowe Wyższej Szkoły Bankowej w Gdańsku, Gdańsk 2011, t. 13, s. 35-58.

[12] Goranczewski B., Szeliga-Kowalczyk A., Jakość ustug turystycznych i rekreacyjnych, ujęcie holistyczne, CeDeWu, Warszawa 2015.

[13] Gurjeet K., Sharma R.D., Seli N., An Assessment of Internal Market Orientation in Jammu and Kashmir Bank Through Internal Suppliers’ Perspective, „Journal of Management Research" 7/2 (2008), s. 149-176.

[14] Hallowell R., Schilesinger L.A., Zornitsky J., Internal Service Quality, Customer and Job Satisfaction: Linkages and Implications for Management, „Human Resource Planning” 19/2 (1996), s. 20-31.

[15] Hauser J.R., Simester D.I., Wernerfelt B., Internal Customers and Internal Suppliers, ,Journal of Marketing Research” $33 / 3$ (VIII, 1996), s. 268-280.

[16] Hofstede G., Hofstede G. J., Kultury i organizacje, PWE, Warszawa 2007.

[17] Jun M., Cai Sh., Examining the Relationships Between Internal Service Quality and its Dimensions, and Internal Customer Satisfaction, „Total Quality Management" 21/2 (II, 2010), s. 205-223.

[18] Kostera M., Antropologia organizacji. Metodologia badań terenowych, PWN, Warszawa 2013.

[19] Kostera M., Śliwa M., Zarządzanie w XXI wieku. Jakość, twórczość, kultura, Wolters Kluwer, Warszawa 2012.

[20] Kowalczyk J. (red.), „Kodeks” dobrej praktyki zarządzania w organizacjach turystycznych, MSiT, Warszawa 2008 [online].

[21] Kożusznik B., Zachowana człowieka w organizacji, PWE, Warszawa 2011.

[22] Krodkiewska - Skoczylas E., Żarlicka G., Zarządzanie relacjami z klientem, [w:] Klient $w$ organizacji zarzadzanej przez jakość, red. T. Sikora, wyd. Akademii Ekonomicznej w Krakowie, Kraków 2006.

[23] Kroeber A.L., Kluckhohn C., Culture: A Critical Review of Concepts and Definitions, (Peabody Museum of American Archeology and Ethnology Papers 47), MA: Harvard University Press, Cambridge 1952.

[24] Mosahab R., Mahamad O., Ramayah T., Comparison of Service Quality Gaps among Teachers and Students as Internal and External Customers, „International Journal of Marketing Studies” 2/2 (XI, 2010), s. 13-20.

[25] Mullins L.J., Management and Organisational Behaviour, „Pearson Education”, 2007.

[26] PN-EN ISO 9000:2006, Systemy zarządzania jakościa, podstawy i terminologia, wyd. PKN, Warszawa 2006.

[27]PN-EN ISO 9001:2009, Systemy zarządzania jakościa. Wymagania, wyd. PKN, Warszawa 2009.

[28] Schein E., Organizational Culture and Leaderschip, Jossey Bass, San Francisco 1992.

[29] Sikorski Cz., Kierunki zmian w kulturach organizacyjnych, [w:] Metody zarządzania kultura organizacyjna, red. Ł. Sułkowski, Cz. Sikorski, Difin, Warszawa 2014.

[30] Sikorski Cz., Kultura organizacyjna w instytucji, wyd. UŁ, Łódź 1990. 
[31] Sikorski Cz., Zachowania ludzi w organizacji, PWN, Warszawa 2002.

[32] Szeliga-Kowalczyk A., Zmienność procesów a dysfunkcje spoteczne w organizacji, [w:] Spoleczne aspekty zarzadzania procesami, red. E. Mazur-Wierzbicka, P. Zwiech, Szczecin 2016, s. 22-32.

[33] Szeliga-Kowalczyk A., Teachers' occupational burnout syndrome, ,, Jagiellonian Journal of Management” 4/2015, s. 353-367.

[34] Szeliga-Kowalczyk A., Work - Life Balance as Seen by Women, based on own research, „Proceedings of IAC-MEM 2016 in Bratislava”, 6-7 VII 2016.

[35]Zbiegień-Maciąg L., Kultura organizacji. Identyfikacja kultur znanych firm, PWN, Warszawa 2005.

\section{INTERNAL CLIENT AND ORGANIZATIONAL CULTURE}

The aim of this article is to present the impact of organizational culture on internal customer perspective: manifestations, such as symbols, ways of Communication and rituals, are among four types of culture contained in the model of competing values. Also, they represent contemporary trends occurring in the organizational culture and its impact on the internal customer. This article is a review. The second and third chapters introduce the reader to the essence of the internal customer, and organizational culture in the light of literature. The fourth and fifth chapters demonstrate, respectively the interactions that occur between the internal client, as subjectively classified by the authors, and the manifestations and types of organizational culture and its trends, characteristic of modern times. The authors conclude that, in the greatest extend, hierarchical culture does not favour to the internal customer, while the best conditions for cooperation and for establishing partnership relations in action offers the cooperative culture. They underline the fact that the modern times are followed by the hybridization of cultures. There are also arising the unusual cultures that constitute the mark of the present times as for example the individualist culture that, due to its high degree of flexibility, provides a good environment for the functioning of the internal customer. Such attributes of the organization culture as: symbols, the way of communication or rituals, have great impact on the internal customer considered by the authors in each of the three adopted prospects.

Keywords: stakeholder, supplier, process approach, artifacts, values.

DOI:10.7862/rz.2017.hss.3

Przestano do redakcji: styczeń 2017 r.

Przyjęto do druku: marzec $2017 \mathrm{r}$. 